\title{
Report of the Joint Leprosy - Tuberculosis Project in Paraguay
}

\author{
A E ALVARENGA \\ Departmento de Lepra, Ministerio de Salud Publica y Bienestar \\ Social, Asunción, Paraguay
}

Following a rewarding initial experience in the treatment of leprosy and tuberculosis with the combination of rifampicin and Isoprodian and taking into account the excellent results of the Malta-Project, the Paraguayan Government, through its Ministry of Health, resolved to initiate an eradication programme of both these diseases which constitute important public health problems in the country.

The realization of the programme was made possible by means of an agreement of cooperation existing between the Government of Paraguay and the German Leprosy Relief Association (DAHW) of Würzburg, and in addition counting on the consultantship - on the technical level—of Professor E Freerksen of the Medical and Biological Research Institute, Borstel.

For the execution of the mixed programme, use was made of the existing infrastructures for leprosy and tuberculosis control.

Concerning the organization of the programme, a central directory, encompassing leprosy and tuberculosis control was created. The Director of the Department for Leprosy Control, Ministry of Health, is in charge of the programme coordination. It should also be mentioned that the leprosy programme is a vertical programme and this proved to be the most efficient way of dealing with the majority of problems at all levels.

Meanwhile the tuberculosis programme is of a horizontal nature, being integrated into the General Health Services.

In the public health approach to both of these diseases there are common characteristics:

1 Treatment is predominantly ambulatory, leaving a small number of patients in need of hospitalization.

1.1 For leprosy patients, under the Ministry of Health, there are many health centres all over the country, the Institute of Tropical Medicine in Asunción, and for cases with advanced incapacities, the leprosarium Santa Isabel of Sapucai. 
1.2 Under the Faculty of Medicine; the relevant wards of the University Hospital in the capital.

1.3 Under private institutions; the Mennonite Hospital km. 81 and the ward of the Patronate for leprosy patients, also in Asunción.

2 For tuberculosis patients:

2.1 Under the Ministry of Health; the Sanatorium Juan Max Boettner.

2.2 Under the Faculty of Medicine, Asunción; the Tuberculosis Service of the University Hospital.

3 In these and other centres patients are not subjected to any kind of segregation and, if necessary, will be attended by other specialists like any other patient. This acceptance by official centres of leprosy patients inspires confidence, thus strengthening the voluntary examination of household contacts and most important, the regularity of treatment.

4 Therapy, including laboratory examinations, is free of charge.

5 The same combined drug therapy is used for both diseases, therefore the Leprosy Service is in charge of drug storage and distribution, safeguarding a close supervision on the utilization of medicaments. For the purpose of the day-to-day management of the joint programme, this has been divided into two sections. First, a leprologist is in charge of the leprosy section, and secondly, a tuberculosis specialist takes care of the TB section. Both these specialists have their offices at the Ministry of Health.

\section{The leprosy section of the joint programme}

The following steps were taken during the preparatory phase:

The provision of intensive information on the efficiency of the combined therapy with Isoprodian-rifampicin, mainly to the decision-taking levels of the Ministry of Health. Thus we try to assure the programme support by the highest national authority.

Intensive theoretical and practical training of medical officers, laboratory and nursing staff collaborating with the programme.

Organizing a central dermatological (including leprosy) clinic and a laboratory for clinical and bacteriological tests. These serve as a centre for treatment, training and reference for doctors, nurses, biochemists and laboratory technicians.

Coordinating the programme with government health centres in order to establish skin and leprosy clinics, and, if needed, to provide hospitalization for leprosy patients.

Safeguarding the provision of drugs. 


\section{INITIATION OF THE PROGRAMME}

Officially, the programme was initiated in September 1979 when the first clinic was opened in Asunción for the treatment of leprosy patients with the combination Isoprodian-rifampicin. This clinic, which happens to be the best developed one of the entire programme, functions full-time and is situated in the same building as the Central Health Centre of the Government. Here, highly qualified dermatologists are taking care of leprosy and other dermatological patients. A well-equipped laboratory is functioning, also full-time, in an annex to this clinic and carries out the relevant tests for leprosy patients.

\section{PROGRAMME DEVELOPMENT}

There was a gradual extension of the programme, linked to the existing public health infrastructure. At this time we have three treatment centres in Asunción and 12 centres in the interior of the country. During the present year, the programme is further expanded to additional towns and villages. To this end, medical officers of government health centres are undergoing a specific training which will enable them to diagnose and treat leprosy patients living inside their area of responsibility.

\section{THE CHEMOTHERAPEUTIC COMBINATION USED}

During the period 1979-1984, the combination Isoprodian-rifampicin was used in the presentation of two separate dragees. In October 1984, a four-drug combination, namely Isoprodian-RMP was introduced, in one single tablet with the following composition: rif ampicin, $150.0 \mathrm{mg}$; isoniazid, $87.5 \mathrm{mg}$; prothionamide, $87.5 \mathrm{mg}$; and dapsone (DDS) $25.0 \mathrm{mg}$.

This new form of presentation offers the following practical advantages: the combination of substances in adequate proportions inside a single tablet facilitates optimum dosage.

The regular ingestion of the medication by the patient is greatly eased by the fact that he only has to take one tablet at a time.

\subsection{The dosage}

This scheme, which depends on the body-weight, is shown below:

$\begin{array}{llll}\text { Patients up to } & 15 \mathrm{~kg} & \text { take } & 1 \text { tablet daily } \\ \text { Patients up to } & 30 \mathrm{~kg} & \text { take } & 2 \text { tablets daily } \\ \text { Patients up to } & 45 \mathrm{~kg} & \text { take } & 3 \text { tablets daily } \\ \text { Patients up to } & 60 \mathrm{~kg} & \text { take } & 4 \text { tablets daily } \\ \text { Patients up to } & 75 \mathrm{~kg} \text { and above } & \text { take } & 5 \text { tablets daily. }\end{array}$

Drug ingestion is daily, from Monday to Saturday, with a break on Sunday. 
Duration of therapy is variable, depending upon the clinical and bacteriological progress of each patient. Disregarding in this context the clinical forms (I-B-TL) of leprosy, the minimum period of treatment is 6 months with an average of about 14 months.

\subsection{The supply of Isoprodian-RMP}

The Department of Leprosy provides Isoprodian-RMP directly to each health centre in accordance with the number of patients on treatment. The drug is deposited under the care of the nursing services and is issued on medical order to the patient at the time of his check-up. Each supply covers a period of 30 days when the patient returns for his clinical and bacteriological controls. The daily drug intake is not supervised since the patient takes medication at home.

The good results we are having with this method of administration are demonstrated by the following facts: the high regularity of patients attending at the clinic or health centre; the favourable clinical and bacteriological evolution of the disease; and the low rate of absconding cases.

\section{NUMBER, DISTRIBUTION AND FOLLOW-UP OF LEPROSY PATIENTS TAKING PART IN THE PROGRAMME}

A total of 6000 cases are estimated to exist in the country. For the development of the programme it was taken into account that the country has 3258 million inhabitants and that 4957 leprosy patients are in the active register; of these, some $31 \%$ of the population and $34 \%$ of registered cases are concentrated inside an area of $2852 \mathrm{sq} \mathrm{km}$ comprising the city of Asunción and the Central Department.

In the first instance, in September 1979, the work started in these two areas from where it was gradually extended to those parts of the country having the highest demographical concentration and a well-developed public health infrastructure.

In time the programme was expanded to other departments. Since the beginning of the programme, the results obtained with the combination Isoprodian-RMP have been most rewarding, particularly regarding the fast cure of patients followed by the reduction of endemic foci.

The specific programme output has been highly satisfactory. This is best evidenced by the following data: total of estimated cases, 6000; total of registered cases, 4957; under treatment with Isoprodian-RMP, 1623 (27\%).

Of these 1623 cases, admitted to the programme, the situation is summed up in Table 1.

Of the 794 cases on observation, 343 were released and taken off the register having completed 3-6 years of post-therapy observation.

It should be mentioned that there are several cases that have been under observation for more than 6 years since ceasing treatment without having 
Table 1

\begin{tabular}{lrr}
\hline Case situation & Number & $(\%)$ \\
\hline Under post-treatment observation & 794 & $(49 \cdot 0)$ \\
Receiving treatment & 687 & $(42 \cdot 4)$ \\
Absconders & 80 & $(5 \cdot 0)$ \\
Deaths & 27 & $(1 \cdot 6)$ \\
Interruptions of therapy & 35 & $(2 \cdot 0)$ \\
Total: & 1623 & $(100 \cdot 0)$ \\
\hline
\end{tabular}

relapsed. The exception is one patient for whom therapy had to be re-started. Of the 27 deaths, not one can be attributed to the specific antileprosy treatment.

The 35 cases which interrupted chemotherapy with Isoprodian-RMP, are accounted for either because of a premature change of medication in a few, mostly private clinics, or of other intercurrent diseases requiring an interruption of specific antileprosy therapy.

\section{The tuberculosis section of the programme}

\section{OBJECTIVES}

The high aims of this programme required the creation of a national tuberculosis register. At present, this covers $53 \%$ of the country population incorporating the most populous sanitary regions. New areas are being added in accordance with the planned extension of the programme.

The immediate programme objective is a speedy reduction of the morbidity and mortality rates, aiming at the cure of all cases.

Doubtless, this aim, whose realization is subject to availability of funds, implies a relatively fast programme extension in order to achieve a total population coverage.

\section{THE PROGRAMME DEVELOPMENT}

The above-mentioned programme aims imply a step-by-step extension, starting in 1979 in the area of the capital and its surrounding populations as well as in several indigenous settlements in the vast Paraguayan area of the Chaco (western region).

In 1981 the programme incorporated the Departments of Paraguarí, Cordillera and the Alto Parana. These areas correspond to the I and IX Sanitary Regions. Other Departments will be added in due course. 
In 1984 the TB programme reached a population of about 1.6 million, some $50 \%$ of the country's inhabitants.

\section{ORGANIZATION}

The fight against tuberculosis is integrated into the general health services of the country, implying medical attention for the TB patient by the government health centres which provide the necessary human and material resources.

Regarding the indigenous population, the anti-tuberculosis service can count on the collaboration of the National Association for the Help for the Indigenous Population and, in some instances, is also assisted by paramedical field workers (Promotores de salud).

Concerning the anti-TB service provided by health centres, a medical practitioner attends TB patients once weekly or more of ten if needed. In the smaller health units the anti-tuberculosis service naturally is of a more limited nature; however it still includes investigations regarding respiratory symptoms, sputum collection and examination by the nearest reference laboratory.

The Central Government Laboratory and the Institute of Tropical Diseases, both in Asunción, serve as TB reference centres and provide the relevant training. In the interior of the country this function is taken over by the Regional Health Centres.

The anti-tuberculosis programme now incorporates 38 localities, including 69 centres providing medical assistance, 22 of which are inside indigenous settlements.

\section{PERIOD OF TREATMENT}

The short-term therapy with Isoprodian-RMP so far has shown good results. For the majority of patients, treatment is ambulatory, controlled but selfadministered.

The minimum period of treatment is five months but this can be prolonged if required by the clinical-bacteriological evolution. This drug-combination is indicated for all forms of the disease, regardless of the extension or severity of the lesion, age, sex or pretreatment. The dosage is the same as that for leprosy patients given and discussed in Section 3.1.

\section{COLLABORATION WITH OTHER INSTITUTIONS}

The following associations and institutions collaborate together with the Ministry of Health in the national tuberculosis programme: The Paraguayan Institute for the Indigenous population (INDI); The Paraguayan Association for the Indigenous population (API); The Mennonite Association or Cooperative Service to the Indigenous populations (ASCIM); The Anglican Church; The 
German Association for Technical Cooperation (GTZ); The Oblatos de Maria; and The Chair for Respiratory Diseases of the Faculty of Medicine, University of Asunción.

\section{RESULTS}

During the period 1979-1984, 5853 tuberculosis cases were detected, or in other words, $25 \%$ of the total estimated number of patients $(22,812)$ existing in the country.

This situation is summed up in Table 2 .

The number of patients that abandoned treatment and those who left the area (16.4 and $14.0 \%$ respectively), could be explained by the fact that there is a high percentage of migrant people.

Also it could be explained because the information system and the system of registration were not so efficient at the beginning of the programme. The majority of deaths are reported from specialized institutions and refer to advanced cases.

The introduction of the combination Isoprodian-RMP constitutes a most important advance in the fight against leprosy and tuberculosis. Principally this is because of its rapid action and outstanding efficiency, coupled with relatively short periods of treatment.

Table 2

\begin{tabular}{lrr}
\hline Case situation & Number & $(\%)$ \\
\hline Cured & 3135 & $(53 \cdot 5)$ \\
Abandoned treatment & 961 & $(16 \cdot 4)$ \\
Left the area & 821 & $(14 \cdot 0)$ \\
Died & 385 & $(6 \cdot 7)$ \\
Actually on treatment & 551 & $(9 \cdot 4)$ \\
\hline Total & 5853 & $(100 \cdot 0)$ \\
\hline
\end{tabular}

In the light of these promising results, the ambitious goal of planned disease eradication which has no parallels in other programmes, imposes the need for continuing the ongoing programme until its final realization. To fulfil this goal it is imperative that the joint TB-Leprosy Programme can count on the continuation of the invaluable support of the German Leprosy Relief Association (DAHW). This great challenge has found the backing of the Paraguayan Government and its people almost from the onset of the programme. 